San Jose State University

SJSU ScholarWorks

Mineta Transportation Institute Publications

$6-2020$

\title{
A Multi-Objective Optimization Model to Minimize the Gap in Accessibility to Multi-Use Paths While Maximizing the Economic Efficiency of Active Transportation Investments for Fresno, California
}

Chih-Hao Wang

California State University, Fresno

Follow this and additional works at: https://scholarworks.sjsu.edu/mti_publications

Part of the Civil Engineering Commons, and the Transportation Engineering Commons

\section{Recommended Citation}

Chih-Hao Wang. "A Multi-Objective Optimization Model to Minimize the Gap in Accessibility to Multi-Use Paths While Maximizing the Economic Efficiency of Active Transportation Investments for Fresno, California" Mineta Transportation Institute Publications (2020). https://doi.org/10.31979/mti.2020.1913

This Report is brought to you for free and open access by SJSU ScholarWorks. It has been accepted for inclusion in Mineta Transportation Institute Publications by an authorized administrator of SJSU ScholarWorks. For more information, please contact scholarworks@sjsu.edu. 


\section{SJSU SAN SOSES SART}

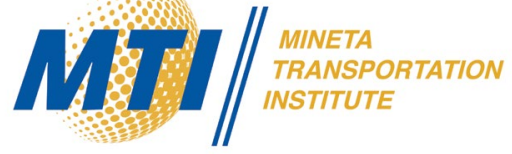

A Multi-Objective Optimization Model to Minimize the Gap in Accessibility to Multi-Use Paths while Maximizing the Economic Efficiency of Active Transportation Investments for Fresno, California

Chih-Hao Wang, PhD

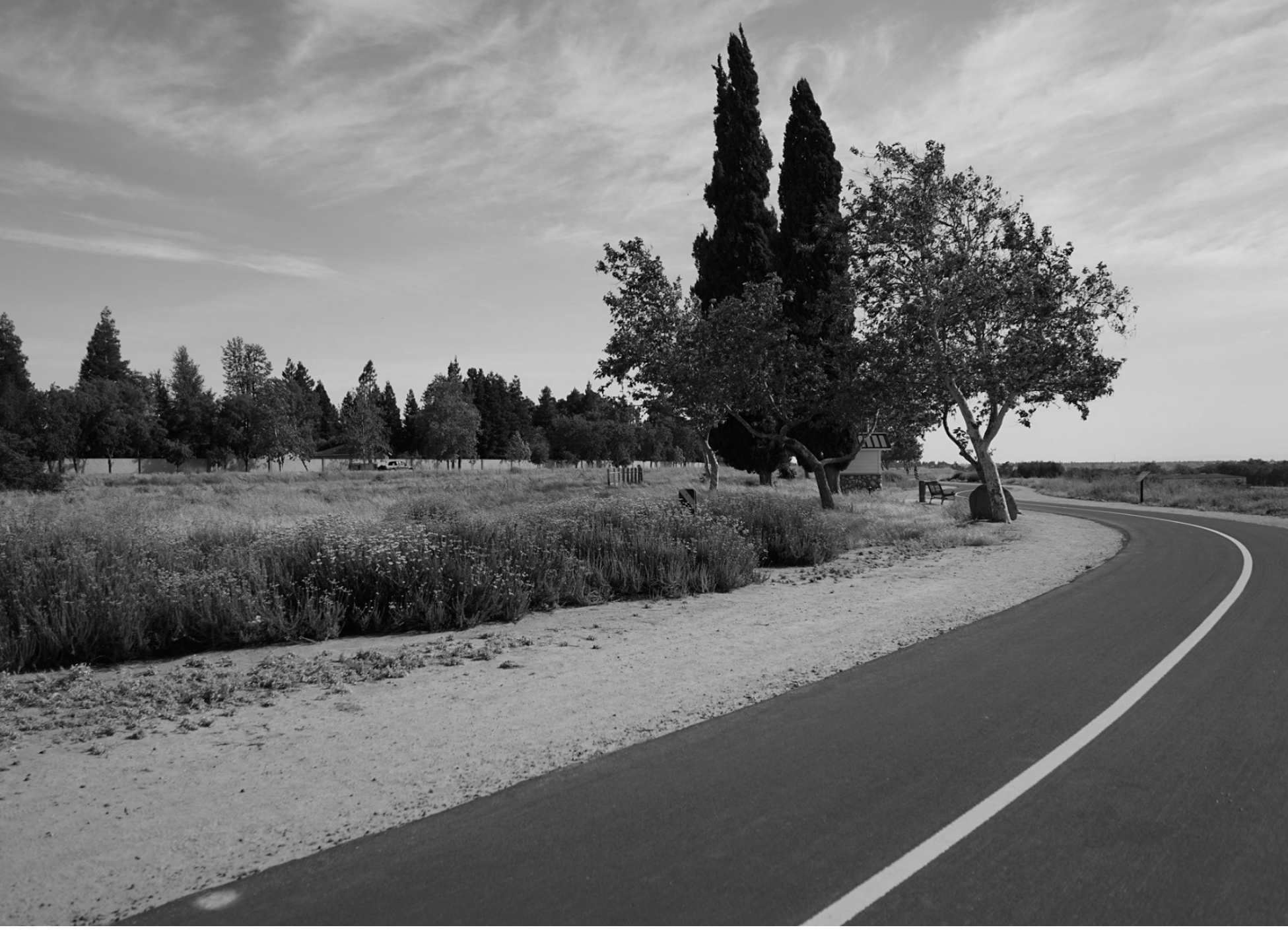




\section{MINETA TRANSPORTATION INSTITUTE}

Founded in 199I, the Mineta Transportation Institute (MTI), an organized research and training unit in partnership with the Lucas College and Graduate School of Business at San José State University (SJSU), increases mobility for all by improving the safety, efficiency, accessibility, and convenience of our nation's transportation system. Through research, education, workforce development, and technology transfer, we help create a connected world. MTI leads the four-university. MTI leads the four-university California State University Transportation Consortium funded by the State of California through Senate Bill I.

MTl's transportation policy work is centered on three primary responsibilities:

\section{Research}

MTI works to provide policy-oriented research for all levels of government and the private sector to foster the development of optimum surface transportation systems. Research areas include: bicycle and pedestrian issues; financing public and private sector transportation improvements; intermodal connectivity and integration; safety and security of transportation systems; sustainability of transportation systems; transportation / land use / environment; and transportation planning and policy development. Certified Research Associates conduct the research. Certification requires an advanced degree, generally a Ph.D., a record of academic publications, and professional references. Research projects culminate in a peer-reviewed publication, available on TransWeb, the MTI website (http://transweb.sjsu.edu).

\section{Education}

The Institute supports education programs for students seeking a career in the development and operation of surface transportation systems. MTI, through San José State University, offers an AACSBaccredited Master of Science in Transportation Management and graduate certificates in Transportation Management, Transportation Security, and High-Speed Rail Management that serve to prepare the nation's transportation managers for the 2 I st century. With the active assistance of the California Department ofTransportation (Caltrans), MTI delivers its classes over a state-of-the-art videoconference network throughout the state of California and via webcasting beyond, allowing working transportation professionals to pursue an advanced degree regardless of their location. To meet the needs of employers seeking a diverse workforce, MTl's education program promotes enrollment to under-represented groups.

\section{Information and Technology Transfer}

MTI utilizes a diverse array of dissemination methods and media to ensure research results reach those responsible for managing change. These methods include publication, seminars, workshops, websites, social media, webinars, and other technology transfer mechanisms. Additionally, MTI promotes the availability of completed research to professional organizations and journals and works to integrate the research findings into the graduate education program. MTl's extensive collection of transportation- related publications is integrated into San José State University's world-class Martin Luther King, Jr. Library.

\section{Disclaimer}

The contents of this report reflect the views of the authors, who are responsible for the facts and accuracy of the information presented herein. This document is disseminated in the interest of information exchange. The report is funded, partially or entirely, by a grant from the State of California. This report does not necessarily reflect the official views or policies of the State of California or the Mineta Transportation Institute, who assume no liability for the contents or use thereof. This report does not constitute a standard specification, design standard, or regulation. 
REPORT 20-21

A MULTI-OBJECTIVE OPTIMIZATION MODEL TO MINIMIZE THE GAP IN ACCESSIBILITY TO MULTI-USE PATHS WHILE MAXIMIZING THE ECONOMIC EFFICIENCY OF ACTIVE TRANSPORTATION INVESTMENTS FOR FRESNO, CALIFORNIA

Chih-Hao Wang, PhD

June 2020

A publication of

Mineta Transportation Institute

Created by Congress in 1991

College of Business

San José State University

San José, CA 95192-0219 


\section{TECHNICAL REPORT DOCUMENTATION PAGE}

1. Report No. 20-21

4. Title and Subtitle

A Multi-Objective Optimization Model to Minimize the Gap in Accessibility to MultiUse Paths While Maximizing the Economic Efficiency of Active Transportation Investments for Fresno, California

2. Government Accession No.
7. Authors

Chih-Hao Wang, PhD

9. Performing Organization Name and Address

Mineta Transportation Institute

College of Business

San José State University

San José, CA 95192-0219

12. Sponsoring Agency Name and Address

State of California SB1 2017/2018

Trustees of the California State

University

Sponsored Programs Administration

401 Golden Shore, 5th Floor

Long Beach, CA 90802
3. Recipient's Catalog No.

5. Report Date

June 2020

6. Performing Organization Code

8. Performing Organization Report CA-MTI-1913

\section{Work Unit No.}

11. Contract or Grant No. ZSB12017-SJAUX

13. Type of Report and Period Covered Final Report

14. Sponsoring Agency Code

15. Supplemental Notes

DOI: $10.31979 / \mathrm{mti} .2020 .1913$

\section{Abstract}

This research examines the accessibility to multi-use paths in a variety of neighborhoods in Fresno, California. This study aims to develop a multi-objective optimization modeling framework to be used by decision makers in transportation and policy to maximize the total accessibility to multi-use paths across the city while minimizing the gap between low- and high- accessibility neighborhoods by an optimal allocation of active transportation. Researchers calculate accessibility to multi-use paths by measuring the total length of multi-use paths (walkway and bikeway) a resident could reach from their own Census block group with a 30-minute cycling ride. The study employs a geographically weighted regression (GWR) model to capture the local relationships between accessibility to multi-use paths and previous transportation investments (walkways, bikeways, and primary and secondary roads), while controlling for other socioeconomic factors. The marginal-effect analysis for the GWR results categorizes the areas within Fresno into economically efficient, inefficient, and indifferent locations for further investments. The researchers embed the GWR results into a multi-objective optimization modeling framework to improve accessibility to multi-use paths over the city and simultaneously address inequality in active-transportation accessibility. This research provides decision makers with insight into the problem of making of an economically-efficient and socially-equal active transportation plan accessible to people from diverse backgrounds with the ultimate goal of fostering public health.

\section{Key Words}

Nonmotorized transportation, accessibility, equity, optimization

\section{Distribution Statement}

No restrictions. This document is available to the public through The National Technical Information Service, Springfield, VA 22161
19. Security Classif. (of this report) Unclassified
20. Security Classif. (of this page) Unclassified
21. No. of Pages

19
22. Price 


\section{Copyright $\odot 2020$ \\ by Mineta Transportation Institute \\ All rights reserved}

DOI:
10.31979/mti.2020.1913
Mineta Transportation Institute College of Business
San José State University
San José, CA 95192-0219

Tel: (408) 924-7560

Fax: (408) 924-7565

Email: mineta-institute@sjsu.edu

transweb.sjsu.edu 


\section{ACKNOWLEDGMENTS}

This research was supported by the 2019 research grant awarded by the Fres-no State Transportation Institute (FSTI) at California State University, Fresno.

The authors thank Editing Press for editorial services, as well as MTI staff, in-cluding Executive Director Karen Philbrick, Ph.D.; Deputy Executive Director Hilary Nixon, Ph.D.; Graphic Designer Alverina Eka Weinardy; and Executive Administrative Assistant Jill Carter. 


\section{TABLE OF CONTENTS}

$\begin{array}{ll}\text { Executive Summary } & 1\end{array}$

$\begin{array}{ll}\text { I. Introduction } & 2\end{array}$

$\begin{array}{ll}\text { II. Background } & 3\end{array}$

III. Modeling Metodology 4

$\begin{array}{ll}\text { IV. Modeling Results } & 11\end{array}$

$\begin{array}{ll}\text { V. Conclusion } & 14\end{array}$

$\begin{array}{lr}\text { Bibliography } & 16\end{array}$

$\begin{array}{lr}\text { About the Author } & 18\end{array}$

$\begin{array}{lr}\text { Peer Review } & 19\end{array}$ 


\section{LIST OF FIGURES}

1. Standardized Accessibility to Multi-Use Paths 5

2. Predicted Accessibility to Multi-use Paths Using the GWR Model 7

3. Local Significant Coefficients of Variable WALK \& BIKE 8

4. Local Significant Coefficients of Variable PRIM \& SECO 9

5. Changes in MUP Accessibility with the $10 \%$ Growth in Transportation Infrastructure

6. Optimal Walkway Allocations 12

$\begin{array}{ll}\text { 7. Optimal Bikeway Allocations } & 12\end{array}$

8. Optimal Primary Road Allocations 13

9. Optimal Secondary Road Allocations 13 


\section{LIST OF TABLES}

1. Descriptive Statistics of Explanatory Variables 6

2. Estimations of Accessibility Models $\quad 7$ 


\section{EXECUTIVE SUMMARY}

- This study aims to develop a multi-objective optimization modeling framework to maximize the total accessibility to multi-use paths while minimizing the gap between low- and high- accessibility neighborhoods by an optimal allocation of active transportation investments for Fresno, California.

- Accessibility to multi-use paths is calculated for Fresno, California. The research team measures the total length of multi-use paths (walkway and bikeway) a resident could reach from their own block group with a 30-minute cycling ride.

- A geographically weighted regression (GWR) model is used to capture the local relationships between accessibility to multi-use paths and previous transportation investments (walkway, bikeway, and primary and secondary roads), while controlling for other socioeconomic factors.

- The marginal-effect analysis for the GWR results indicates economically efficient, inefficient, and indifferent locations for further transportation investments.

- The GWR results are embedded into a multi-objective optimization modeling framework to improve accessibility to multi-use paths across the city and simultaneously address inequality in active-transportation accessibility.

- The methodology of this multi-objective optimization modeling provides decision makers a new insight into the problem of making an economically efficient and socially equitable active transportation plan to foster public health. 


\section{INTRODUCTION}

The city of Fresno in California is among those cities with the highest concentration of poverty in the country (Cytron, 2009). Fresno residents, especially those from socially disadvantaged neighborhoods, are facing an array of economic, education, and health challenges due to poor transport connectivity in this car-oriented city. A previous Mineta Transportation Institute (MTI) study pointed out that a significant difference in accessibility to multi-use paths by cycling exists between white and non-white, as well as young and elder, neighborhoods (Wang and Chen, 2019). To promote a fair active transportation framework, it is worth exploring an optimal allocation of future active transportation investments that could maximize the total accessibility to multi-use paths while minimizing the gap between low- and high-accessibility neighborhoods across the city of Fresno.

In active transportation planning, planners usually develop a set of criteria to prioritize the locations for future investments, especially when a city is on a tight budget. For instance, criteria used to prioritize the locations for additional multi-use paths (walkway and bikeway) in Fresno include: (1) proximity to key destinations (bus stops, schools, parks, activity centers), (2) travel demand from origins (population and employee density), (3) care of socioeconomically disadvantaged neighborhoods (low income, low vehicle ownership), (4) level of traffic stress and collisions, and (5) comments from the public (City of Fresno, 2016). The goal of an active transportation plan is to encourage residents, especially those from socioeconomically disadvantaged neighborhoods, to engage in more physical activities. The basic idea is to foster public health and address inequalities through improving accessibility to multi-use paths across the city. Nevertheless, the problem of these designed criteria is usually a result of politics set on the principle that "everyone has a share," which is not necessarily the best way to either attend to the economic efficiency of transportation investments or address the inequality issues involved in multi-use-path accessibility.

This study is intended to address this decision-making problem by developing an optimization modeling framework that could balance economic efficiency and accessibility equity. In this study, accessibility to multi-use paths is first calculated, using the network analysis package in ArcGIS, for Fresno, California. Then, a geographically weighted regression (GWR) model is used to estimate the local relationships between multi-use-path accessibility and the current active transportation network, while controlling for other socioeconomic factors. The GWR estimates are then embedded in an optimization modeling framework, through an optimal allocation of $10 \%$ growth in four transportation investments (walkway, bikeway, and primary and secondary roads), to maximize the total accessibility to multiuse paths while minimizing the total difference in accessibility across the 410 block groups in Fresno. Solving this multi-objective optimization model has implications for decision makers seeking to effectively and efficiently build an active transportation environment and address accessibility and inequality issues. 


\section{BACKGROUND}

Based on the well-known cumulative-opportunity theory, accessibility can be seen as the total amount of a specific urban opportunity (jobs, schools, libraries, hospitals, restaurants, parks, multi-use paths, and so on) that a resident in a city can reach within a certain travel time by a certain transportation mode (walking, cycling, public transit, and driving). Many past studies have tried to apply this concept to measure accessibility to a certain opportunity across a city using geographical information system (GIS) technology. Most of these studies also tried to explore the relationships between such calculated accessibility metrics and the built environment features of a city (land uses, transportation networks, and other location effects) (El-Geneidy et al., 2016). In these studies, accessibility was usually defined as a function of transportation infrastructure and connectivity, built-environmental features, and sociodemographic factors.

In this realm of accessibility research, most studies were done using a global (ordinary) regression model to examine whether a spatial mismatch exists between calculated accessibility metrics, previous transportation investments, and socially disadvantaged groups. A drawback of this global regression modeling approach is that it neglects the spatially varied effects of transportation variables (Wang and Chen, 2017). In other words, a global regression model does not produce local relationships and therefore the global results fail to provide information about effective locations for future transportation investments. To help with decision making, the marginal-effect analysis of a local regression model would be able to point to effective, ineffective, and indifferent locations for transportation investments or to point out a specific socially-disadvantaged group as the benefactor of social programs. These all echo the need for a geographically weighted regression (GWR) model in this study to capture such local relationships between multi-use-path accessibility and the current active transportation network.

Another stream of accessibility research focuses on the assessment of transportation policies (Fan et al., 2010; Karou and Hull, 2014). Most studies set out to test and compare alternative transportation investments. Although this approach could help point out the best alternatives for transportation investments among a set of options, decision makers would more so like to know about what exactly to do in terms of investment allocation that would meet the goal of a certain transportation policy. For instance, a decision maker might be interested in knowing how active transportation investments are allocated to produce the maximum economic efficiency to accessibility or the minimum gap in accessibility city-wide. In this case, an optimization modeling framework can be used to serve this purpose (Wang, 2019; Wang and Guldmann, 2015). However, there is little research focusing on such optimization problems that would maximize total accessibility across a city, minimize the gap between low- and high-accessibility neighborhoods, or do both at the same time as a multi-objective optimization problem, and thus this study is needed. 


\section{MODELING METODOLOGY}

\section{Accessibility to Multi-Use Paths}

The cumulative-opportunity approach mentioned above is employed to calculate accessibility to multi-use paths in this study. We count the number of a specific urban opportunity that can be reached within a certain travel time, distance or cost by using a certain transportation mode (Geurs and Van Wee, 2004). We select cycling as the transportation mode to calculate accessibility to multi-use paths because it has been long considered as a transportation mode for active travel. From the OpenStreetMap (OSM), a cycling network dataset is built in ArcGIS for Fresno. Street links are extracted, including primary, primary_link, secondary, secondary_link, tertiary, tertiary_link, un-classified, residential, living_street, service, track, cycleway, footway, bridleway, pedestrian, and path.

In short, multi-use paths in this study include: (1) walkway (footways and pedestrian sidewalks), and (2) bikeway (cycle ways and paths), given by the OSM dataset. A 30-minute service area is constructed at the block group level using this built cycling network dataset. The constructed service area is then used to calculate the accessibility to multi-use paths as:

$$
A C_{i}^{m p_{-} c y}=\sum_{j=1}^{J} D_{j} L_{j}
$$

where

$A C_{-}^{m p_{-} c y}$ is the total length (mile) of all multi-use paths (walkway and bikeway) reachable through cycling for a block group $i$;

$D_{j}$ is a binary value as 1 if the multi-use path segment $j$ is within the service area and 0 otherwise;

$L_{j}$ represents the length (mile) of the multi-use path segment $j$.

Figure 1 illustrates the standardized result of calculated accessibility to multi-use paths for Fresno. High accessibility block groups cluster in Northeast Fresno, declining outward in a ring pattern. 


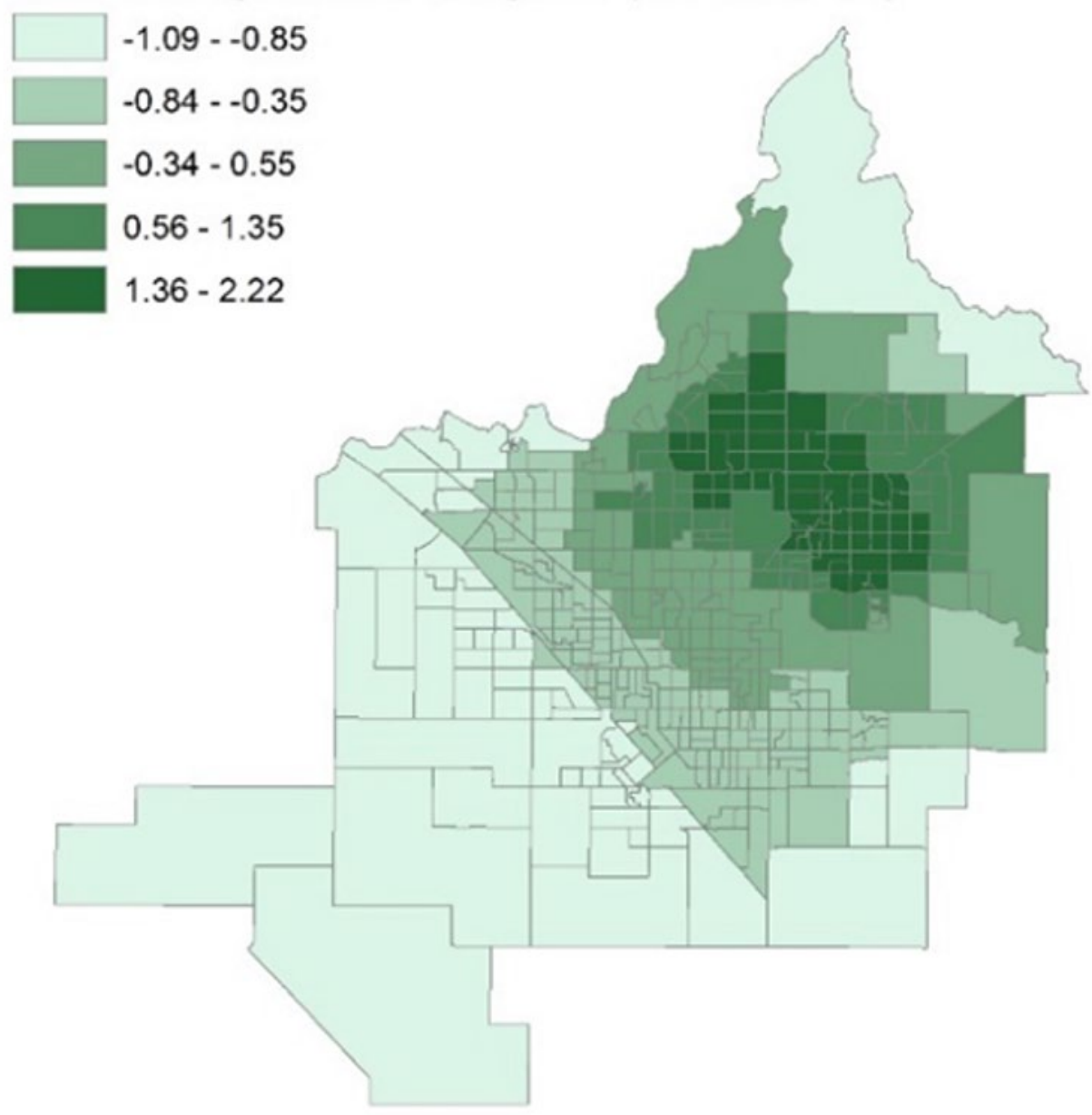

Figure 1. Standardized Accessibility to Multi-Use Paths

\section{GWR Modeling}

An ordinary regression and a geographically weighted regression (GWR) model are respectively used to examine the global and local relationships between calculated accessibility metrics and the current transportation network. The idea is to interpret the GWR estimated results in the context of the global estimated results. First, Equation (1) can be formulated as a linear regression (LR) model of multi-use-path (MUP) accessibility on seven explanatory variables: walkway (WALK), bikeway (BIKE), primary road (PRIM), secondary road (SECO), street density (STDN), income (INCO), and non-white share (NONW). The descriptions of these explanatory variables are presented in Table 1. The estimated results of the LR model are presented in Table 2. The LR model produces an adjusted- $R^{2}$ of 0.27 and the results can be used to compare the spatial pattern of MUP accessibility and that of any of the explanatory variables.

From Figure 1, North Fresno not only has better accessibility to multi-use paths, but it is also a relatively wealthy area with more active transportation investments. As a result, it is not surprising that the spatial pattern of MUP accessibility is positively related to that of variables WALK, BIKE, PRIM, STDN, and INCO. In addition, a block group with a higher 
share of non-white population (NONW) tends to have lower MUP accessibility. Interestingly, the secondary roads (SECO) do not contribute much to MUP accessibility because they are intensively distributed in the south.

Table 1. Descriptive Statistics of Explanatory Variables

\begin{tabular}{llll}
\hline \multicolumn{1}{c}{ Variable } & \multicolumn{1}{c}{ Description } & \multicolumn{1}{c}{ Mean } & \multicolumn{1}{c}{ S. D. } \\
\hline WALK & Miles of paths and footway in a block group & 0.20 & 0.97 \\
BIKE & Miles of cycleway in a block group & 0.07 & 0.33 \\
PRIM & Miles of primary roads in a block group & 0.23 & 0.46 \\
SECO & Miles of secondary roads in a block group & 7.68 & 8.68 \\
STDN & Street density (mile/sq.mi.) in a block group & 21.72 & 7.83 \\
INCO & Median household income (\$) in a block group & 48,410 & 29,209 \\
NONW & Percentage of non-white in a block group & 36.08 & 18.57 \\
\hline No. of observation & & & \multicolumn{2}{c}{410} \\
\hline
\end{tabular}

The drawback of this LR model is that it neglects the effects of transportation connectivity. High transportation investments would not necessarily result in high MUP accessibility if the allocated multi-use paths do not connect to the core cycling network in the city. A GWR model can capture such connectivity effects by considering the effects of neighboring transportation infrastructure as spatial autocorrelations. The GWR estimated results are also presented in Table 2. The GWR estimation is using a Gaussian kernel weighting function associated with an adaptive bandwidth. An optimal bandwidth with a quantile of $2.27 \%$ is selected, using the Akaike information criterion (AIC) approach. Readers interested in GWR estimation can refer to Fotheringham et al. (2003). Variance inflation factor (VIF) values are also used to measure the increased variance of an estimated coefficient by local collinearity (Wheeler and Páez, 2010; Wheeler and Tiefelsdorf, 2005). The research team did not find serious multicollinearity problems, since all VIF values are lower than the critical value of 10 (Cardozo et al., 2012). The GWR model produces a much larger quasi-global- $R^{2}$ of 0.964 , as compared to that from the LR model (0.272). It also has a much smaller AIC value of 124 , compared to the LR model value of 1043 . Both $R^{2}$ and AIC values suggest that this GWR model well explains the variation in MUP accessibility and better accounts for transportation connectivity effects. Figure 2 illustrates the predicted MUP accessibility to multi-use paths, showing a very similar spatial pattern with Figure 1. 
Table 2. Estimations of Accessibility Models

\begin{tabular}{|c|c|c|c|c|c|c|}
\hline Models & & & GWR & & & LR \\
\hline Variables & Min. & $1^{\text {st }} \mathrm{Qu}$. & Median & $3^{\text {rd }} \mathrm{Qu}$. & Max. & \\
\hline Intercept & -1.14 & -0.72 & -0.11 & 1.11 & 2.00 & -0.08 \\
\hline \multicolumn{7}{|l|}{ Multi-use paths } \\
\hline WALK & -0.99 & -0.06 & 0.01 & 0.07 & 1.31 & 0.10 \\
\hline BIKE & -2.45 & -0.20 & 0.08 & 0.20 & 1.87 & 0.33 \\
\hline \multicolumn{7}{|l|}{ Roads } \\
\hline PRIM & -0.80 & -0.04 & 0.08 & 0.19 & 0.63 & 0.28 \\
\hline SECO & -0.13 & -0.01 & -0.01 & 0.01 & 0.10 & -0.03 \\
\hline STDN & -0.05 & -0.01 & 0.0006 & 0.01 & 0.06 & 0.02 \\
\hline \multicolumn{7}{|l|}{ Socioeconomic factors } \\
\hline INCO (1000\$) & -0.01 & -0.002 & -0.00007 & 0.001 & 0.02 & 0.008 \\
\hline NONW & -0.03 & -0.01 & -0.0007 & 0.0008 & 0.03 & -0.01 \\
\hline Adaptive bandwidth quantile (\%) & & & & & 2.27 & \\
\hline Quasi/Adjusted R² (\%) & & & & & 96.39 & 27.21 \\
\hline AICc/AIC & & & & & 124.22 & 1043.27 \\
\hline
\end{tabular}

Significance: 0.05 in bold

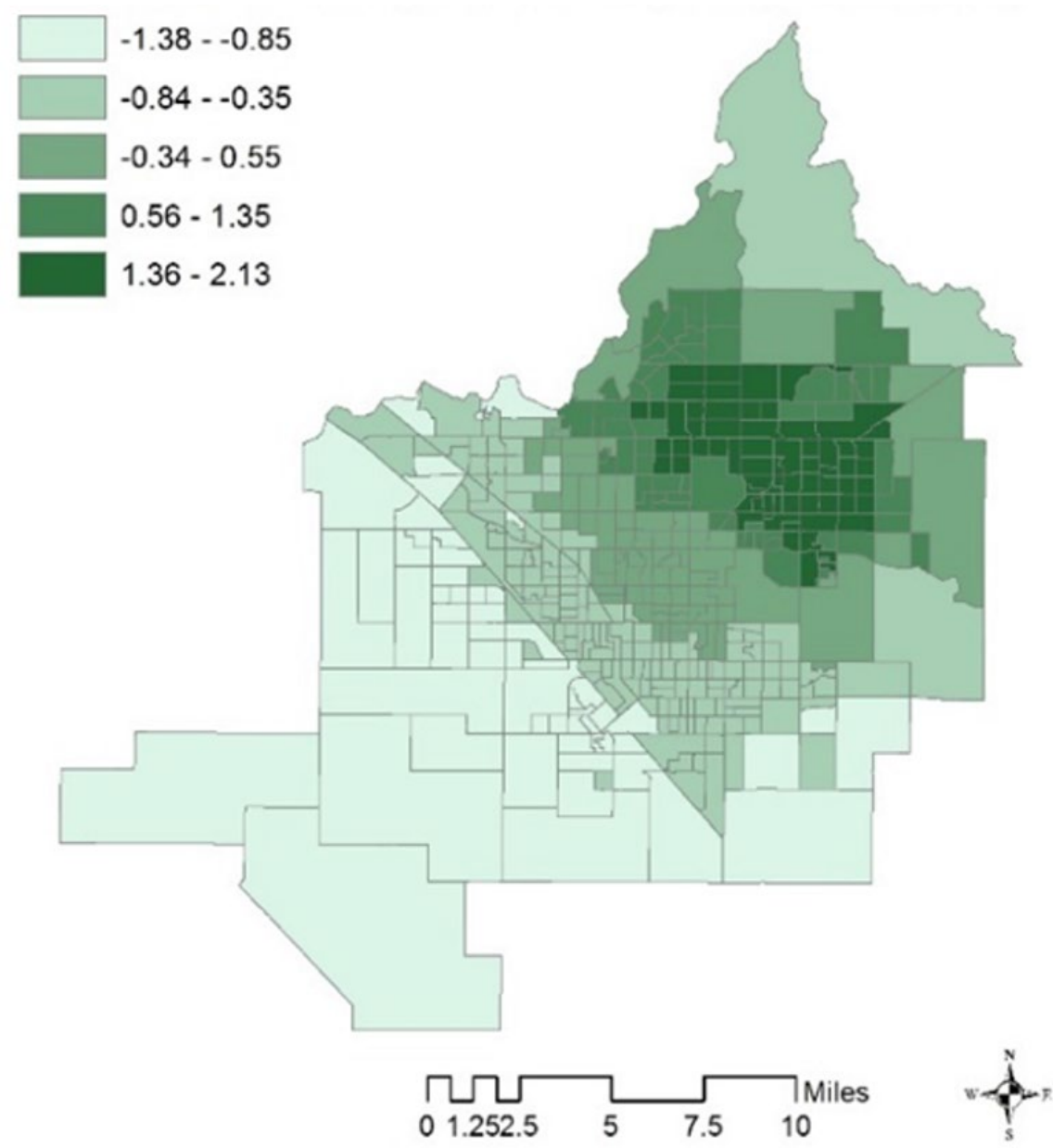

Figure 2. Predicted Accessibility to Multi-use Paths Using the GWR Model 
The significant local coefficients (at the 0.05 level) of variable WALK, BIKE, PRIM, and SECO, together with the corresponding t-values, are mapped in Figure 3 and 4 . In a linear regression model, the marginal-effect analysis reveals the effect to the dependent variable by a unit change in the corresponding explanatory variable, normally indicated by the estimated coefficient. Similarly, the local estimated coefficients in the GWR model represent the increases in MUP accessibility of a unit change in a transportation infrastructure variable across the 410 block groups. In Figure 3 and 4, positive local coefficients are colored in blue and green, while negative values are colored in yellow and red. The shading areas indicate where the local estimates are significant at the 0.05 level. Thus, the significant positive coefficients point to the most effective locations for future transportation investments, while the significant negative ones imply inefficient locations, most likely due to poor transportation connectivity In addition, the insignificant local coefficients indicate indifferent locations for investments.
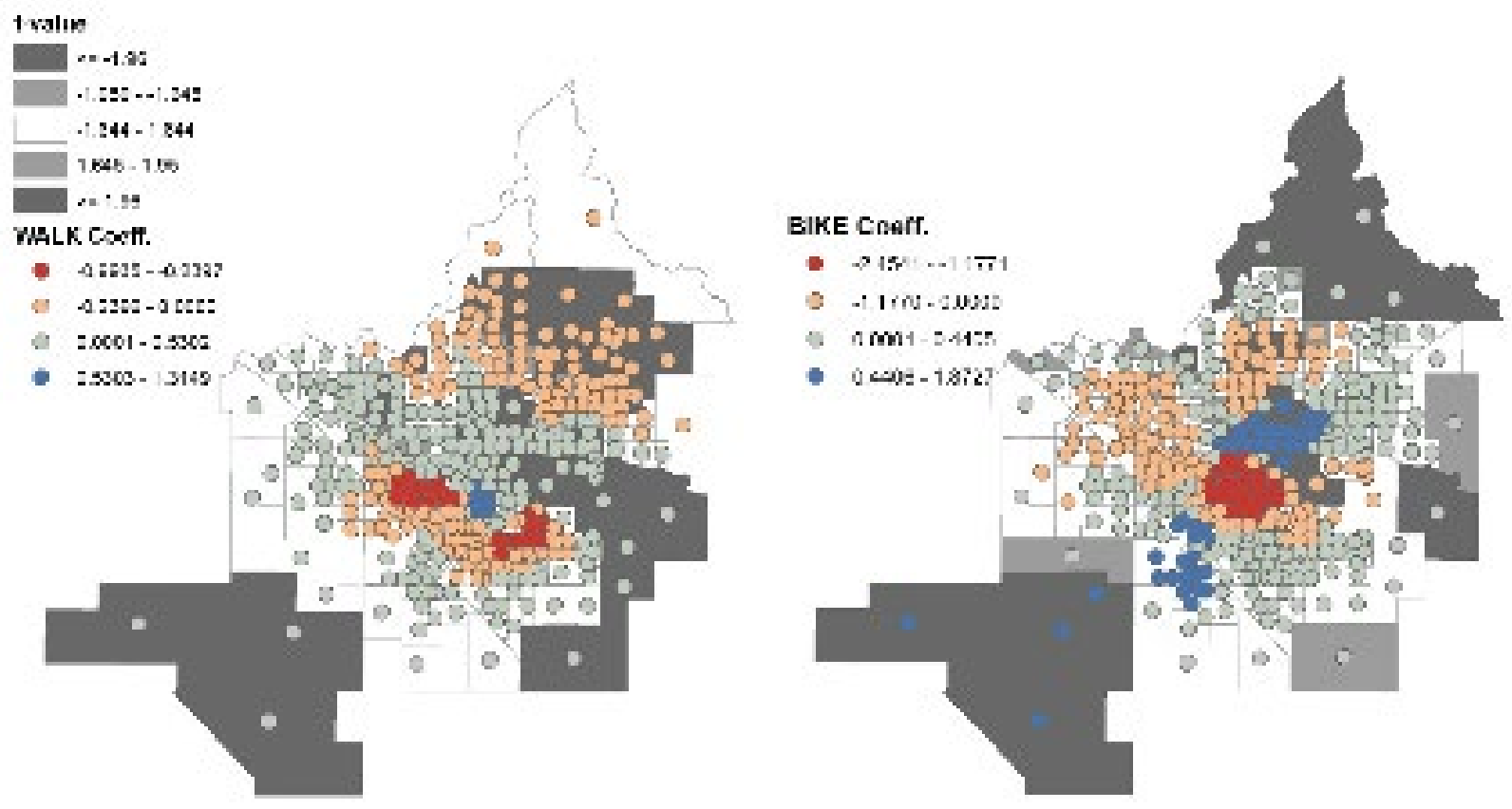

Figure 3. Local Significant Coefficients of Variable WALK \& BIKE 

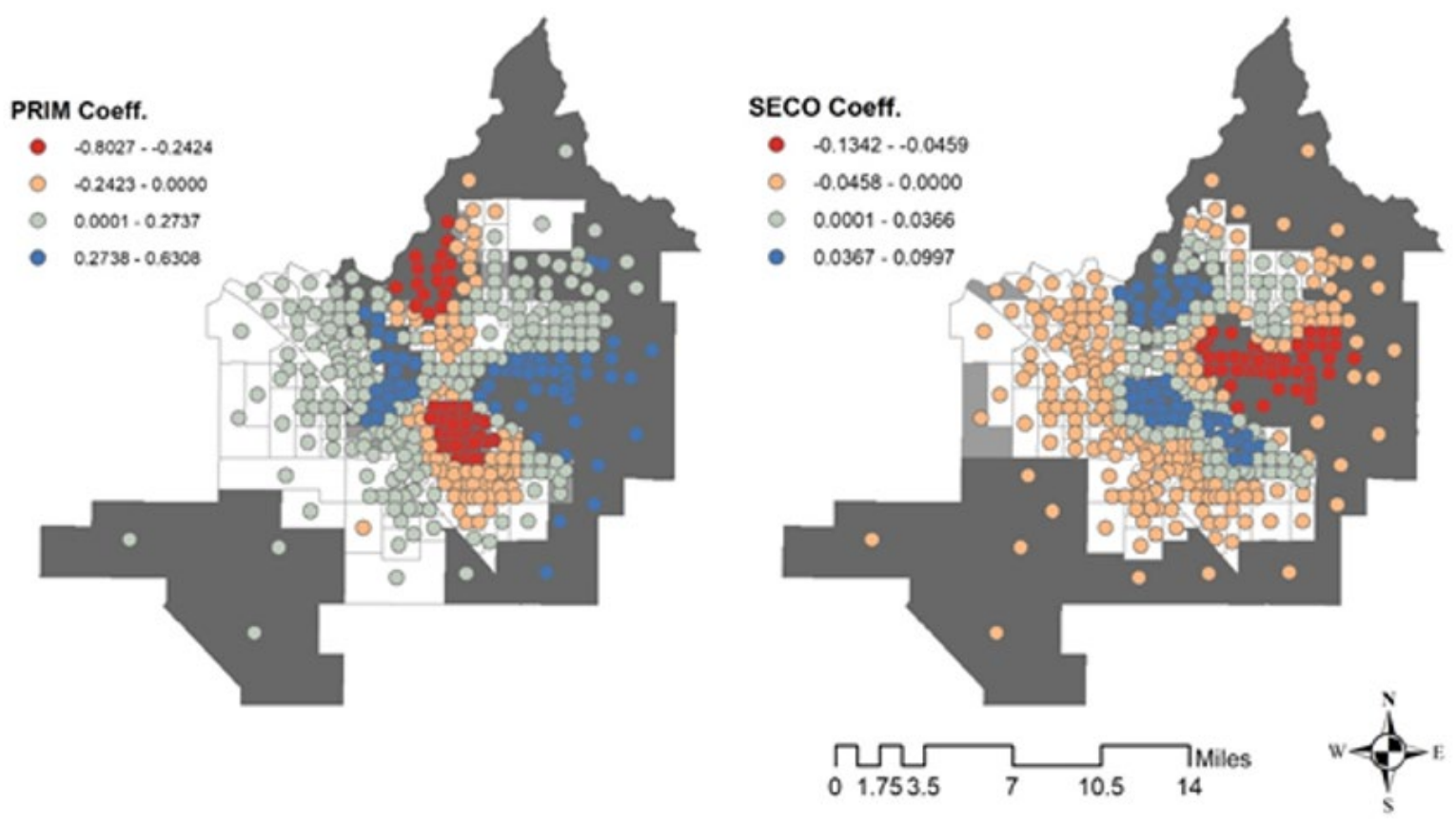

Figure 4. Local Significant Coefficients of Variable PRIM \& SECO

\section{Multi-Objective Optimization Modeling}

The GWR model predicts MUP accessibility so well that the significant estimated coefficients can be embedded in an optimization modeling framework for allocating future transportation investments to meet the goal of an active transportation plan. A multi-objective optimization model is proposed here to incorporate the GWR results and assumes that the estimates remain unchanged, so do the values of the socioeconomic variables (INCO and NONW). The multi-objective function is to maximize the total MUP accessibility while minimizing the total difference in MUP accessibility among the 410 block groups. The endogenous variables are set to be $10 \%$ growth in each of the four transportation infrastructure types (WALK, BIKE, $P R I M, S E C O)$. This optimization model is implemented in the General Algebraic Modeling System (GAMS) with the nonlinear programming solver CONOPT, formulated as follows: 
maximize $A C=\sum_{i=1}^{410}\left(C_{i}-\sqrt{C_{i}^{2}}\right)$,

subject to:

$$
\begin{aligned}
C_{i}= & \beta_{1}\left(u_{i}, v_{i}\right)\left(W A L K_{i}\right)+\beta_{2}\left(u_{i}, v_{i}\right)\left(B I K E_{i}\right)+\beta_{3}\left(u_{i}, v_{i}\right)\left(P R I M_{i}\right)+\beta_{4}\left(u_{i}, v_{i}\right)\left(S E C O_{i}\right)+ \\
& \beta_{5}\left(u_{i}, v_{i}\right)\left(W A L K_{i}+B I K E_{i}+P R I M_{i}+S E C O_{i}\right) / A R E A_{i}+P R E D_{i},
\end{aligned}
$$

$\sum_{i} W A L K_{i}=8.18$,

$\sum_{i} B I K E_{i}=2.73$,

$\sum_{i}$ PRIM $_{i}=9.25$,

$\sum_{i} \operatorname{SECO}_{i}=280.84$,

$W A L K_{i} \leq 0.2$,

$B I K E_{i} \leq 0.07$,

$P R I M_{i} \leq 0.23$,

$\operatorname{SECO}_{i} \leq 6.85$,

$W A L K_{i}, B I K E_{i}, P R I M_{i}, S C_{C O} \geq 0$.

Equation (3) computes MUP accessibility for block group $i$ as a function of future transportation investments, corresponding changes in street density, and the predicted accessibility with the current values of all variables expressed as $P R E D_{i}$. Note that ( $\left.u i, v i\right)$ denotes the centroid coordinates of block group $i$ and only the significant coefficients are used in the function. Equations (4) through (7) state that the sum of transportation infrastructure allocated in the city must be equal to $10 \%$ of the current status as the growth target (8.18 miles for WALK, 2.73 miles for BIKE, 9.25 miles for PRIM, and 280.84 miles for SECO). Equations (8) through (11) state that the increment of transportation infrastructure in a block group must be no more than the average of the current status $(0.2$ mile for WALK, 0.07 mile for $B I K E, 0.23$ mile for PRIM, 6.85 miles for SECO). Equation (12) simply states that all the increments cannot be negative. 


\section{MODELING RESULTS}

Figure 5 illustrates changes in MUP accessibility resulting from the 10\% growth in transportation infrastructure. Obviously, the optimization model improves MUP accessibility to the originally low-accessibility neighborhoods (blue block groups) in the outer rings, while slightly decreasing MUP accessibility to the originally high-accessibility neighborhoods (red block groups) in North Fresno. This active transportation scenario is designed to maximize the total accessibility across the city while minimizing the total differences between low- and high-accessibility block groups.

To achieve this goal, the optimization model is expected to allocate transportation investments only to the lowest-accessibility locations which have significant positive large coefficients (Figure 6, 7, 8, and 9), because they represent the most effective or efficient locations for investments. Note that the optimization will not allocate investments to a high-accessibility location even if it has a positive coefficient, because this will exacerbate the gap between low- and high-accessibility neighborhoods.

When exhausting all available locations, the optimization model would move to indifferent locations (with insignificant coefficients). It is worth noting that the model will try not to allocate investments to high-accessibility locations with significant negative coefficients because this will result in inefficient investments. The problem of these neighborhoods is the poor connectivity to the core active transportation network, not the need for additional investments. In short, the optimization model improves accessibility for Southwest Fresno (low-accessibility neighborhoods) without impairing that in North Fresno (highaccessibility neighborhoods).

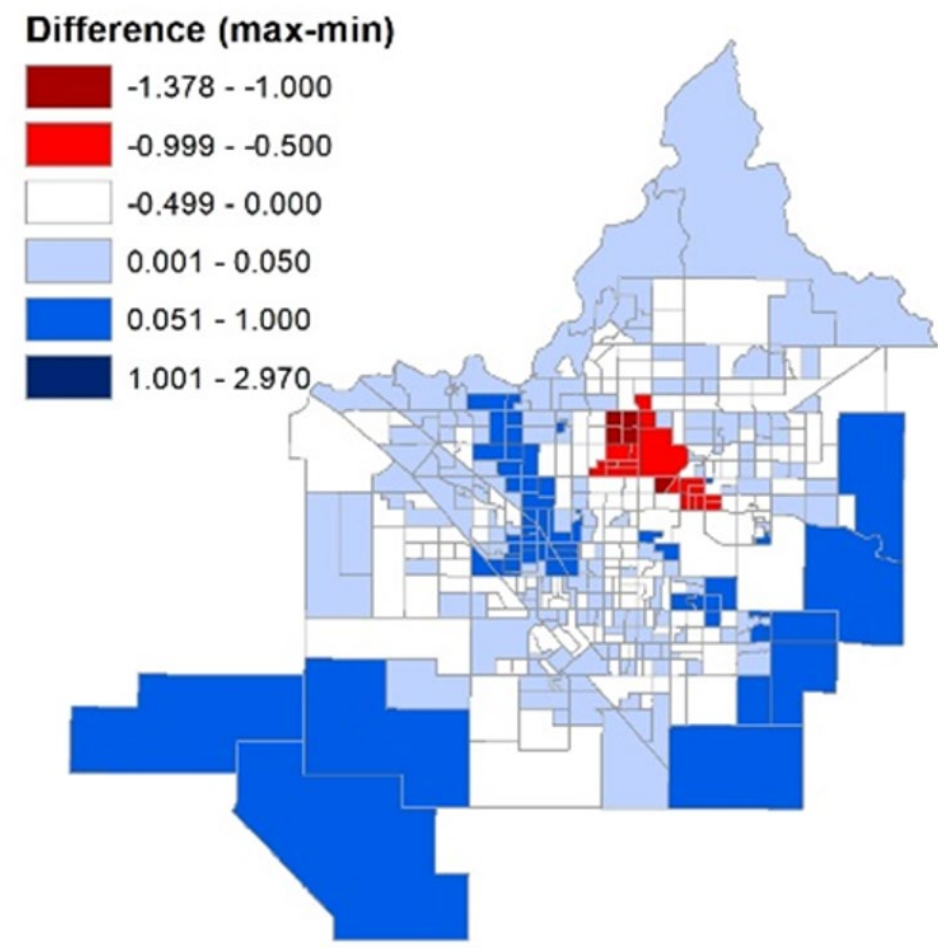

Figure 5. Changes in MUP Accessibility with the $10 \%$ Growth in Transportation Infrastructure 


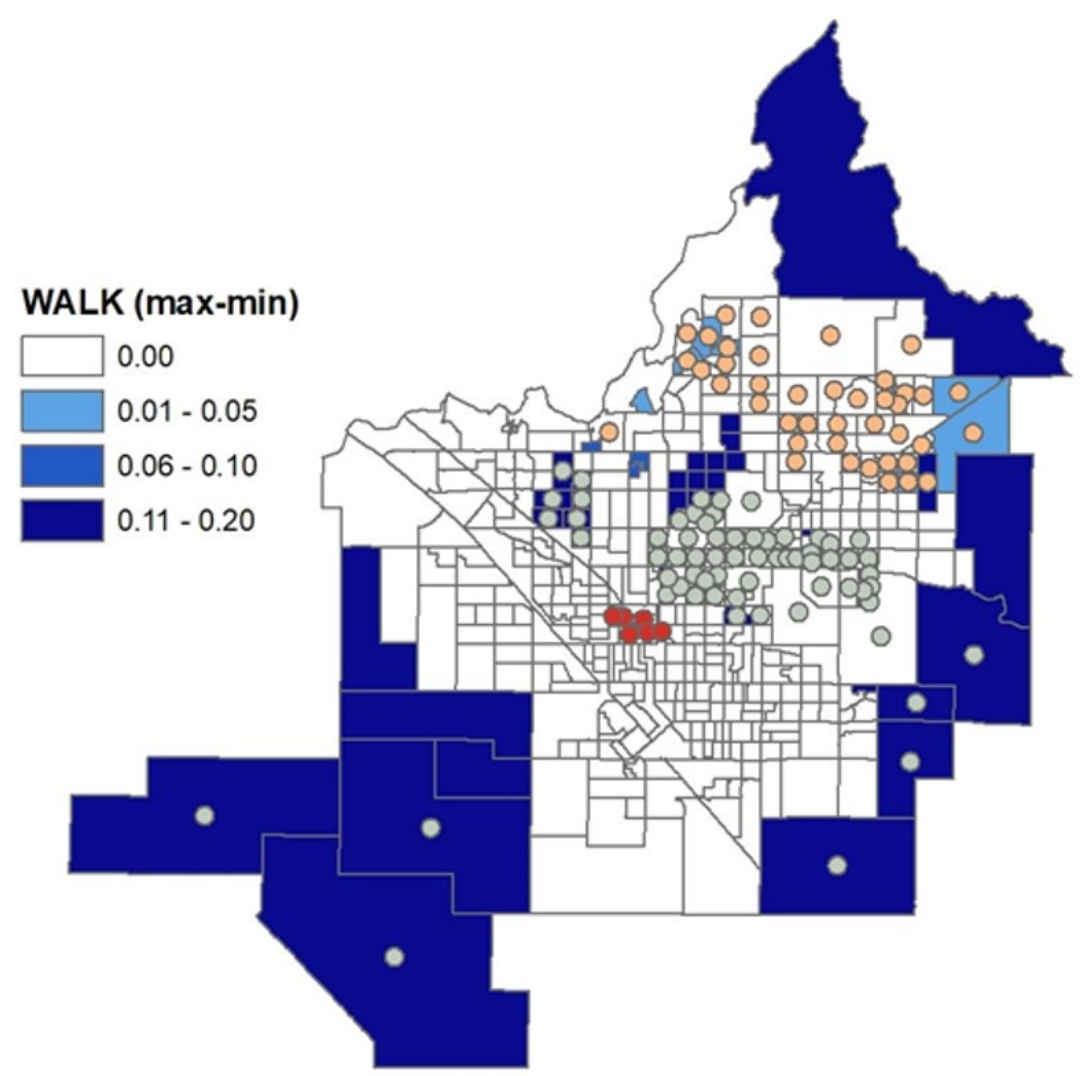

Figure 6. Optimal Walkway Allocations (Miles)

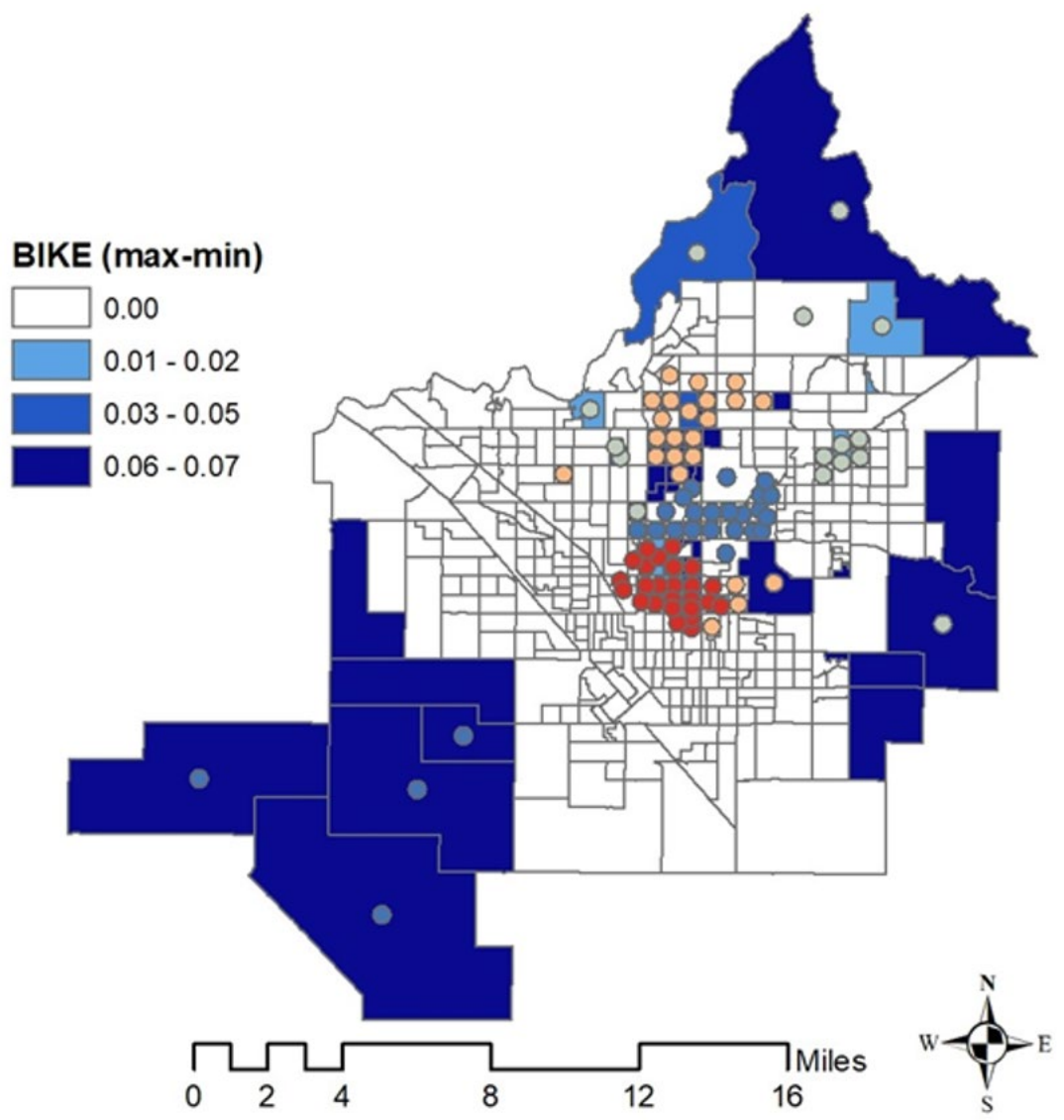

Figure 7. Optimal Bikeway Allocations (Miles) 


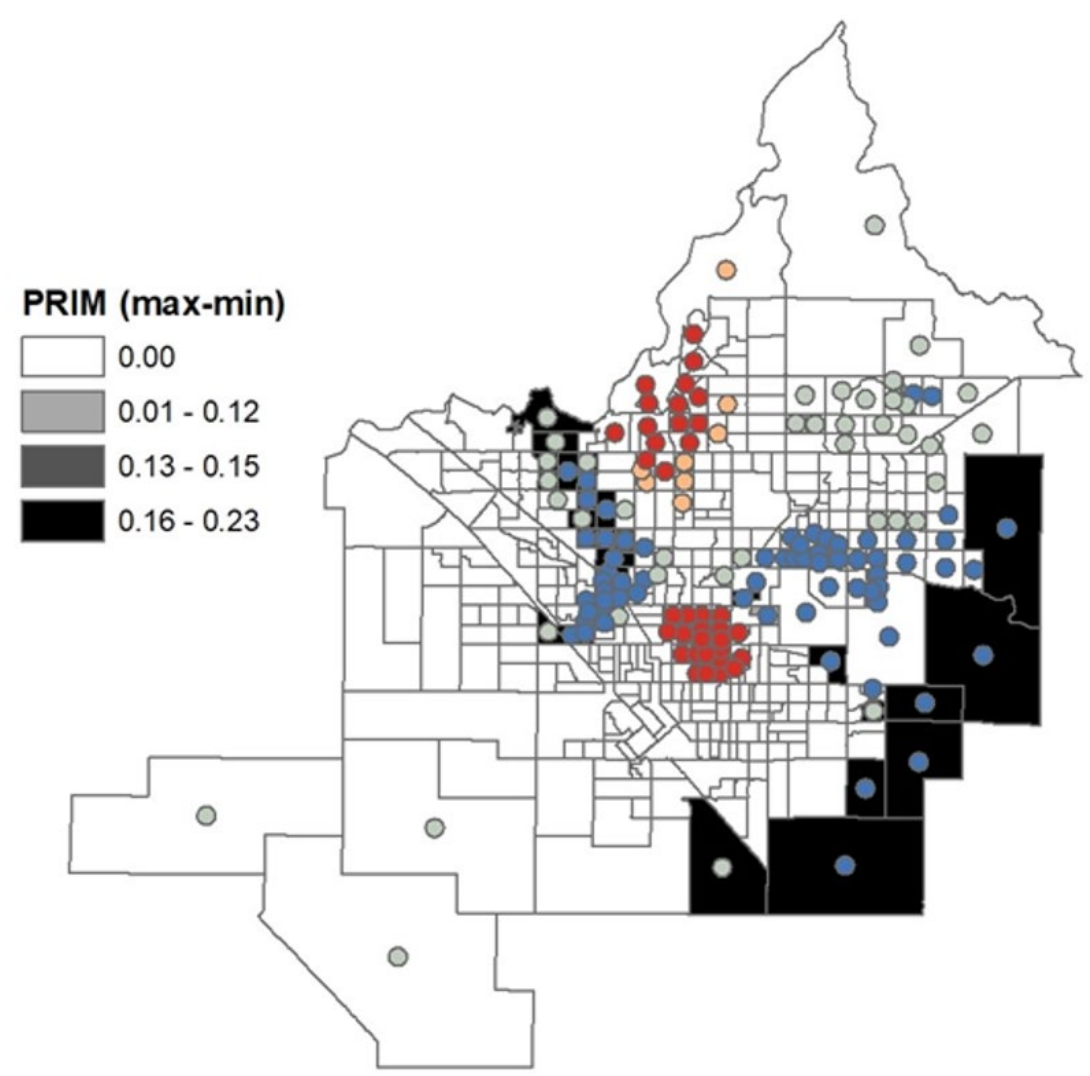

Figure 8. Optimal Primary Road Allocations (Miles)

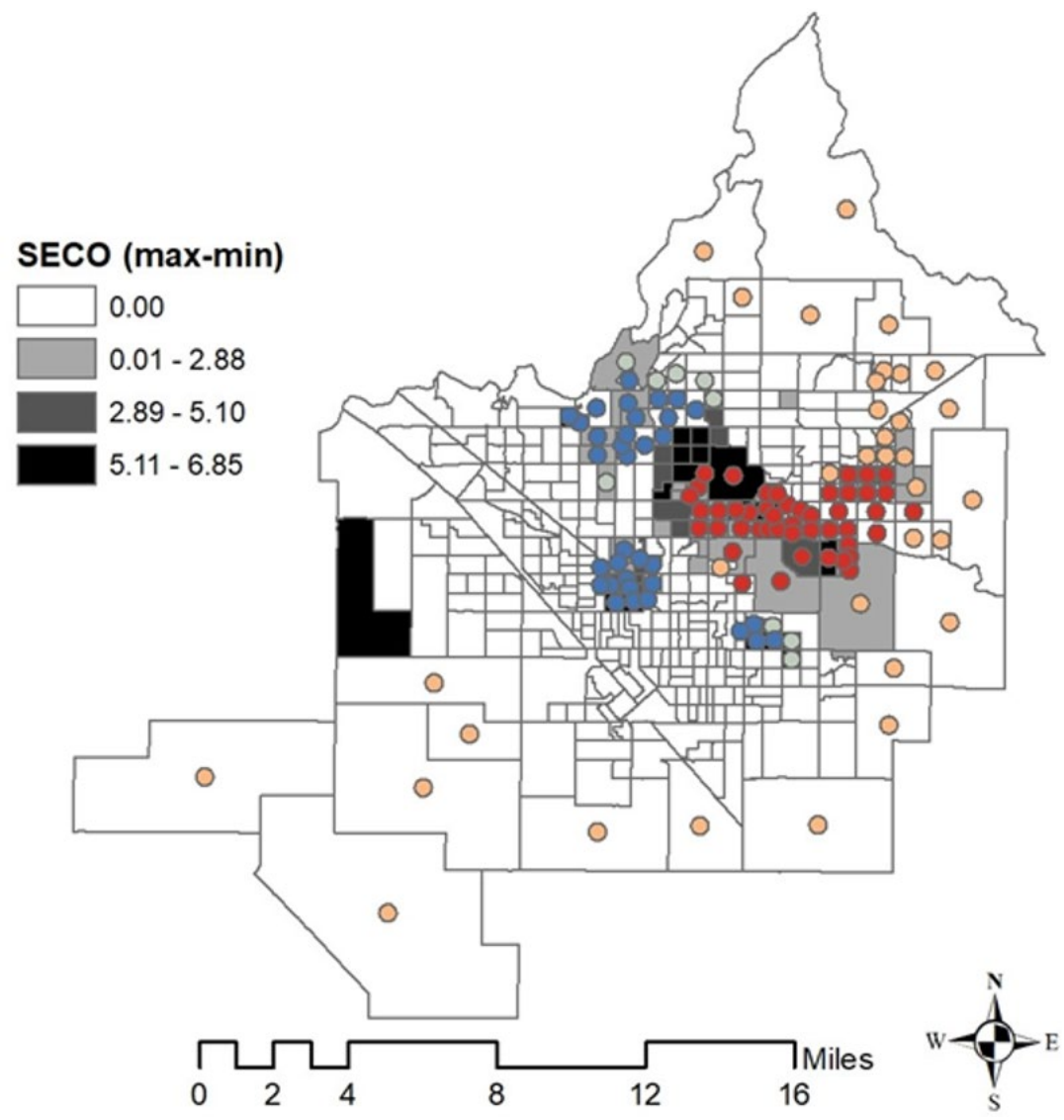

Figure 9. Optimal Secondary Road Allocations (Miles) 


\section{CONCLUSION}

A multi-objective optimization modeling framework has been developed and implemented in the context of Fresno, California to allocate $10 \%$ increments of walkway, bikeway, and primary and secondary roads to maximize the total accessibility to multi-use paths, while minimizing the total difference in accessibility across the city. This study first used a geographically weighted regression (GWR) model to capture local relationships between accessibility to multi-use paths and existing transportation investments. Then, this study developed a multiobjective optimization modeling framework that embeds the statistically estimated GWR function of accessibility to allocate future transportation investments to serve the abovementioned purpose. This optimization modeling framework provides new insight into the problem of allocating transportation investments to achieve economic efficiency and reduce accessibility inequality.

The result of accessibility calculations shows that North Fresno has better multi-use-path accessibility and that South Fresno requires more investments in transportation infrastructure or improvements of active transportation connectivity. Additionally, the proposed optimization model allocated transportation investments only to the lowest accessibility locations where have positive coefficients (i.e. positive local relationships between accessibility and investments). After exhausting all these locations, the model moved to indifferent ones with insignificant coefficients. As a result, the model improved accessibility for Southwest Fresno (low accessibility areas) without impairing the original accessibility in North Fresno (high accessibility areas).

The purpose of an active transportation plan usually aims at improving accessibility to multiuse paths across the city to encourage residents to pursue more physical activities. Also, an active transportation plan usually sets out to address accessibility inequality issues. However, it is rare to incorporate accessibility analysis from the perspective of science into a decisionmaking process to solve this problem. The success of developing an economically efficient and socially fair active transportation framework depends on the understanding of local relationships between multi-use-path accessibility and the current transportation network. In this study, the implementation of the proposed optimization modeling framework, embedded with location relationships, can be seen as a problem-solving example for a hypothetical scenarios (i.e. $10 \%$ of increments of transportation investments) for the city of Fresno to promote public health.

As for policy implications, all the three steps in this study can be used for any city anytime when it is needed, to provide useful planning information in the making of a new active transportation plan or in the reviewing of an existing one, as follows.

1. This study suggests including the calculation of accessibility in active transportation planning. The proposed accessibility analytic approach considers the existing transportation network and accounts for the effects of connectivity. Therefore, we believe that this is a better way to evaluate the physical outcome of previous transportation investments.

2. A GWR modeling could be very useful in active transportation planning, because 
the results reveal efficient (significantly positive), inefficient (significantly negative), and indifferent (insignificant) locations for transportation investments. It is sensible to allocate more investments in the efficient locations to increase multi-use-path accessibility. More interesting, the results also imply that the need of the inefficient locations is not to allocate more walkways and bikeways, but rather to improve the first-to-last-mile connectivity to the core cycling network through all transportation means (i.e. sidewalks and on-road bike lanes).

3. A multi-objective optimization model can be used to determine the optimal locations for future active transportation investments to achieve economic efficiency and reduce accessibility inequality. This is particularly useful when a city is on a tight budget.

Moreover, an active transportation plan is a result of a series of planning decisions and practice, considering local conventions, economic efficiency, social equality, public comments, and lobbying (Sampson et al., 2002). Such a decision is usually subject to public comments. The involvement of public participation in a planning process might result in a compromised outcome that "everyone has a share". For instance, one might see that additional walkway or bikeway is, more or less, allocated to every sub-region of the city in an active transportation plan. Such an allocation of future transportation investments might please everyone but it is not necessarily to be economically efficient. The proposed optimization modeling framework in this study takes both economic efficiency and accessibility inequality into considerations. In the public participation process, the results can be used to better communicate with both groups of residents (socially advantaged and socially disadvantaged groups) that the optimal allocation is economically efficient and socially just. For instance, it would be easier for planners, with the modeling results, to convince either the residents from betteroff neighborhoods that the city is still investing in connectivity to improve accessibility or those from worse-off neighborhoods that the city is trying, in a more effective manner, to address the concern of accessibility inequality. This would help avoid possible pitfalls of public participation. 


\section{BIBLIOGRAPHY}

Cardozo, O.D., García-Palomares, J.C., Gutiérrez, J. “Application of geographically weighted regression to the direct forecasting of transit ridership at station-level." Applied Geography 34 (2012): 548-558.

City of Fresno (2016) Active Transportation Plan, Fresno, CA.

Cytron, N. (2009) The Enduring Challenge of Concentrated Poverty in America Case Study of Fresno, California, Federal Reserve Bank of San Francisco.

El-Geneidy, A., Levinson, D., Diab, E., Boisjoly, G., Verbich, D., Loong, C. "The cost of equity: Assessing transit accessibility and social disparity using total travel cost." Transportation Research Part A: Policy and Practice 91 (2016): 302-316.

Fan, Y., Guthrie, A., Levinson, D.M. "Impact of light rail implementation on labor market accessibility: A transportation equity perspective." Journal of Transport and Land Use 5 (2010).

Fotheringham, A.S., Brunsdon, C., Charlton, M. (2003) Geographically weighted regression: the analysis of spatially varying relationships. John Wiley \& Sons.

Geurs, K.T., Van Wee, B. "Accessibility evaluation of land-use and transport strategies: Review and research directions." Journal of Transport Geography 12 (2004): 127140.

Karou, S., Hull, A. "Accessibility modelling: Predicting the impact of planned transport infrastructure on accessibility patterns in Edinburgh, UK." Journal of Transport Geography 35 (2014): 1v11.

Sampson, R.J., Morenoff, J.D., Gannon-Rowley, T. "Assessing 'neighborhood effects': Social processes and new directions in research." Annual Review of Sociology 28 (2002): 443-478.

Wang, C.-H., Chen, N. "A geographically weighted regression approach to investigating the spatially varied built-environment effects on community opportunity." Journal of Transport Geography 62 (2017): 136-147.

Wang, C.-H., Guldmann, J.-M. "A land-use allocation optimization model to mitigate potential seismic damages." Environment and Planning B: Planning and Design 42 (2015): 730-753.

Wang, C-H. "A Land-Use and Capital-Investment Allocation Optimization Model to Develop a Fair Community Opportunity Framework for Columbus, Ohio." Computers, Environment and Urban Systems 74 (2019): 151-160.

Wang, C-H. and Chen, N. (2019) Developing a Fair Accessibility Framework through 
Green (Non-Auto) Transportation Modes for Fresno, California, August 2019. Final Report to the Mineta Transportation Institute at San José State University.

Wheeler, D., Páez, A. Geographically weighted regression. Teoksessa Fischer M, Getis A.(toim.) Handbook of Applied Spatial Analysis: Software tools, methods and applications. Heidelberg, Springer: 2010.

Wheeler, D., Tiefelsdorf, M. Multicollinearity and correlation among local regression coefficients in geographically weighted regression. Journal of Geographical Systems 7 (2005): 161-187. 


\section{ABOUT THE AUTHOR}

\section{CHIH-HAO WANG, PHD}

Chih-Hao Wang is an associate professor of the Department of Geography and City \& Regional Planning at California State University, Fresno, where he has taught since 2014. He received his Ph.D. (2013) and Master's (2010) degrees in City and Regional Planning from The Ohio State University. Dr. Wang's research focuses on environmental planning from the perspective of natural hazard mitigation. Another of his research interests is the application of spatial statistics to analyze spatial or social interactions in the earthquake process, as well as water management, transportation planning, and community development. His research has been published in journals in areas of environmental planning, transportation, and geography. 


\section{PEER REVIEW}

San José State University, of the California State University system, and the Mineta Transportation Institute (MTI) Board of Trustees have agreed upon a peer review process required for all research published by MTI. The purpose of the review process is to ensure that the results presented are based upon a professionally acceptable research protocol. 


\author{
Founder, Honorable \\ Norman Mineta (Ex-Officio) \\ Secretary (ret.), \\ US Department of Transportation \\ Chair, \\ Abbas Mohaddes (TE 202I) \\ President \& COO \\ Econolite Group Inc. \\ Vice Chair, \\ Will Kempton (TE 2022) \\ Retired \\ Executive Director, \\ Karen Philbrick, PhD \\ (Ex-Officio) \\ Mineta Transportation Institute \\ San José State University \\ Richard Anderson \\ (Ex-Officio) \\ President \& CEO \\ Amtrak \\ David Castagnetti (TE 202 I) \\ Co-Founder \\ Mehlman Castagnetti \\ Rosen \& Thomas \\ Maria Cino (TE 202 I) \\ Vice President \\ America \& U.S. Government \\ Relations Hewlett-Packard Enterprise
}

\author{
Grace Crunican* \\ (TE 2022) \\ Retired
}

Donna DeMartino (TE 202I)

General Manager \& CEO

San Joaquin Regional Transit District

Nuria Fernandez* (TE 2020)

General Manager \& CEO

Santa Clara Valley

Transportation Authority (VTA)

John Flaherty (TE 2020)

Senior Fellow

Silicon Valley American

Leadership Form

Rose Guilbault (TE 2020)

Board Member

Peninsula Corridor

Joint Powers Board

Ian Jefferies (Ex-Officio)

President \& CEO

Association of American Railroads

Diane Woodend Jones

(TE 2022)

Principal \& Chair of Board

Lea + Elliott, Inc.
Therese McMillan

(TE 2022)

Executive Director

Metropolitan Transportation

Commission (MTC)

Bradley Mims (TE 2020)

President \& CEO

Conference of Minority

Transportation Officials (COMTO)

Jeff Morales (TE 2022)

Managing Principal

InfraStrategies, LLC

Dan Moshavi, PhD

(Ex-Officio)

Dean, Lucas College and

Graduate School of Business

San José State University

Takayoshi Oshima (TE 202 I)

Chairman \& CEO

Allied Telesis, Inc.

Toks Omishakin

(Ex-Officio)

Director

California Department of

Transportation (Caltrans)
Paul Skoutelas (Ex-Officio)

President \& CEO

American Public Transportation

Association (APTA)

Dan Smith (TE 2020)

President

Capstone Financial Group, Inc.

Beverley Swaim-Staley (TE 2022)

President

Union Station Redevelopment

Corporation

\section{Jim Tymon (Ex-Officio)}

Executive Director

American Association of

State Highway and Transportation

Officials (AASHTO)

\section{Larry Willis (Ex-Officio)}

President

Transportation Trades

Dept., AFL-CIO

$(\mathrm{TE})=$ Term Expiration

* = Past Chair, Board of Trustees

\section{Directors}

Karen Philbrick, Ph.D.

Executive Director

Hilary Nixon, Ph.D.

Deputy Executive Director

\section{Asha Weinstein Agrawal,}

\section{Ph.D.}

Education Director

National Transportation Finance

Center Director

\section{Brian Michael Jenkins}

National Transportation Security

Center Director

\title{
Research Associates Policy Oversight Committee
}

Jan Botha, Ph.D.

Civil \& Environmental Engineering

San José State University

Katherine Kao Cushing,

\section{Ph.D.}

Enviromental Science

San José State University

Dave Czerwinski, Ph.D. Marketing and Decision Science San José State University
Frances Edwards,

Ph.D.

Political Science

San José State University

Taeho Park, Ph.D.

Organization and Management

San José State University

\section{Christa Bailey}

Martin Luther King, Jr. Library

San José State University

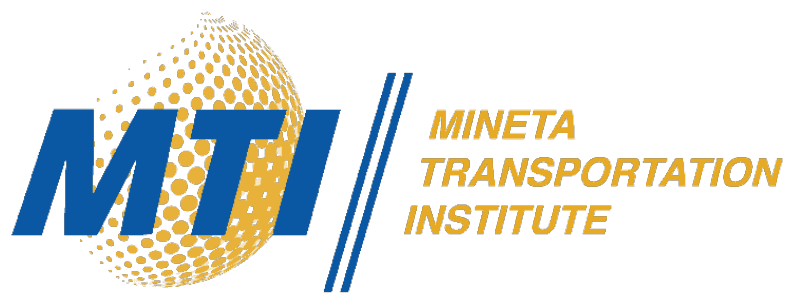

